\title{
Dumbbell Shaped Microstrip Broadband Antenna
}

\author{
Sudeep Baudha (1), Harshit Garg (10, Manish Varun Yadav (i) \\ Department of Electrical and Electronics Engineering, \\ Goa Campus, BITS Pilani, India \\ sudeepb@goa.bits-pilani.ac.in, f20140257@goa.bits-pilani.ac.in, \\ manishvarun21@gmail.com
}

\begin{abstract}
In this article, a dumbbell shaped microstrip broadband microstrip antenna with partial ground plane is presented, The overall dimension of the proposed antenna is $20 \times 15 \times 1.5 \mathrm{~mm}^{3}$ and is fabricated on FR4 substrate which has electrical permittivity of 4.3 and loss tangent of 0.025 . FR4 is a low cost and easily available. The thickness of the substrate is $1.5 \mathbf{~ m m}$. The impedance bandwidth of the proposed antenna is $151.11 \%(3.48 \mathrm{GHz}$ to $25 \mathrm{GHz})$. The peak gain and radiation efficiency of the proposed antenna are $4.5 \mathrm{~dB}$ and $68 \%$ respectively in the operating frequency band. Due to introduction of rings on the edges of the octagon and cutting of circular slots with the rectangular slits in the ground plane the antenna starts resonating from $3.48 \mathrm{GHz}$ to $25 \mathrm{GHz}$. Simulated results are in good agreement with the measured results. The proposed antenna covers partial frequency range for ultra-wide band applications, 3.5/5.5 GHz WiMAX band, 5.2/5.8 GHz WLAN band, 8/12 GHz X-band, 12/18 GHz Ku -band. It can be used in space and satellite communications etc. Curves of radiation pattern and S-parameter of both simulated and measured results are shown. The impedance curves, surface current, radiation efficiency, simulated return losses, gain, and radiation patterns of the proposed antenna are described in the paper.
\end{abstract}

Index Terms - Broadband Antenna, Fractional Bandwidth, Dumbbell Shape, Partial Ground Plane, Satellite Communication

\section{INTRODUCTION}

Microstrip antennas are widely used for X-band, Ku-band, WiMAX band, WLAN band, Ka-band, etc. This is due to their high gain, large bandwidth and many other promising features. Compared to conventional antennas microstrip antennas are low profile, inexpensive and easy to fabricate. They can be integrated with other microstrip components on PCB. The antenna design is directly visible on PCB and thus it provides an easy access for troubleshooting. They are robust when mounted on rigid surfaces. These antennas are thus used in high-performance aircrafts, missiles, rockets and satellites with smooth functioning.

In [1] two wideband antipodal tapered slot (ATS) elements are utilized to configure a fan-like 
structure for generating wide-angle radiation. In [2] by making a parasitic patch and cutting a curved slot in the patch, large impedance bandwidth is obtained. In [3] to enhance the bandwidth a single L-shaped slot is etched out in the ground plane of the circular disc monopole antenna. In [4] the angles and side lengths of the diamond shape slot have been optimized to obtain a multi frequency microstrip antenna useful in $\mathrm{C}$ band space communication systems. A notch in the ground plane is used to obtain lower frequency range and inverted $U$-shaped slot in the radiator patch is used to reject the unwanted frequency band [5]. Rectangular patches and U-shaped slits are introduced in the design to cover a larger frequency bandwidth [6]. By cutting a curved slot in the patch provides large radiation surface for the antenna and thus its efficiency increases [7]. The horizontal gap in the backplane is responsible for enhancing bandwidth both at lower and higher frequencies [8]. Due to addition of circular slots and rectangular slits, antenna starts resonating at higher frequencies [9]. Two symmetrical open-circuit slots are made from the ground plane to achieve an ultra-wideband impedance matching [10]. To achieve lower frequencies a U-shaped valley with multiple slots is developed in the partial ground plane [11].

The process of radiation results in the clusters of moving charges. From [12] to make the antenna more efficient the radiation from its moving charges need to add constructively at desired frequencies and angular directions. Thus to ensure this, proper geometry design, its current distribution, and electrical dimensions are needed. A broadband frequency range is obtained by use of slots in the front and back plane which can be used in ultra-wideband applications of 3.5/5.5 GHz WiMAX band, 5.2/5.8 GHz WLAN band, 8/12 GHz X-band and 12/18 GHz Ku -band [13-14].

The proposed antenna is a dumbbell shaped octagon which has a valley shaped backplane. Compared to other antenna designs which are typically $25 \times 25 \times 1.5 \mathrm{~mm}^{3}$ in dimensions or even large, the proposed antenna is a very low profile antenna with dimensions $20 \times 15 \times 1.5 \mathrm{~mm}^{3}$ only. FR4 substrate having electrical permittivity ( $\varepsilon r$ ) of 4.3 and loss tangent of 0.025 is used in the design. S-parameters results are from $3.48 \mathrm{GHz}$ to $25 \mathrm{GHz}$. Further introduction of two circular slots and vertical rectangular slits in the octagons improved the design results from $16 \mathrm{GHz}$ to $25 \mathrm{GHz}$. Impedance matching takes place with varying parameter ' $x$ ' and results are further improved from $3.7 \mathrm{GHz}$ to $3.48 \mathrm{GHz}$.

\section{DESIGN CONFIGURATION}

Fig. 1 shows the design configuration. The overall size of the antenna is $20 \times 15 \times 1.5 \mathrm{~mm}^{3}$. Substrate used in the antenna is low cost FR-4 material, which has an electrical permittivity of 4.3 and loss tangent 0.025 . Length of the antenna is denoted by ' $\mathrm{L}$ ' and width by ' $\mathrm{W}$ '. The design is dumbbell shaped with the radius of each octagon being $4 \mathrm{~mm}$ and it is represented here by ' $\mathrm{r}$ '. Length of the backplane is Lh. Radius of the two circular slots on the front plane is represented by ' $\mathrm{k}$ '. Distance between two octagons is ' $\mathrm{d}$ ' and it serve as the length of the microstrip line. Its width is denoted by 'Ws'. 


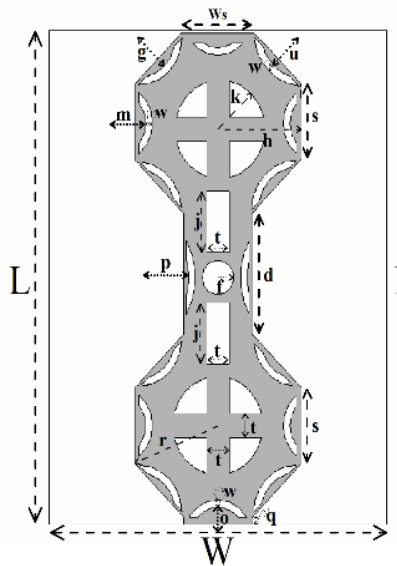

(a)

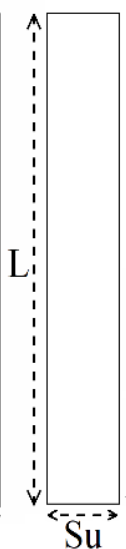

(b)

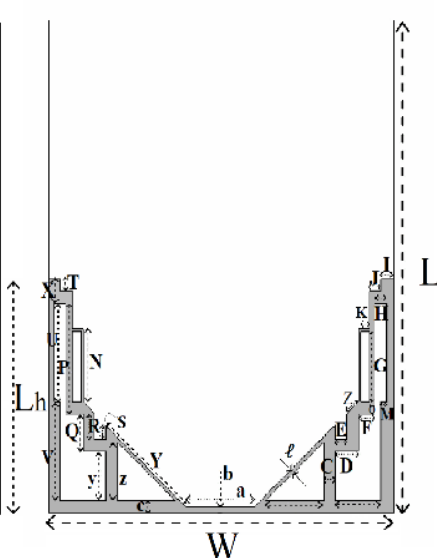

(c)

Fig. 1. Proposed antenna configuration (a) front view (b) side view (c) backplane view.

TABLE 1. DESIGN PARAMETER VALUES

\begin{tabular}{|c|c|c|c|c|c|c|c|c|c|c|c|c|c|}
\hline Parameters & $\mathbf{L}$ & $\mathbf{W}$ & $\mathbf{W s}$ & $\mathbf{L h}$ & $\mathbf{S u}$ & $\mathbf{~}$ & $\mathbf{h}$ & $\mathbf{S}$ & $\mathbf{d}$ & $\mathbf{j}$ & $\mathbf{P}$ & $\mathbf{Q}$ & $\mathbf{a}$ \\
\hline $\begin{array}{c}\text { Values } \\
(\mathbf{m m})\end{array}$ & 20 & 15 & 3 & 9.5 & 1.5 & 4 & 3.696 & 3.061 & 4.917 & 2.5 & 4.5 & 1.5 & 3.032 \\
\hline Parameters & $\mathbf{u}$ & $\mathbf{g}$ & $\mathbf{p}$ & $\mathbf{m}$ & $\mathbf{0}$ & $\mathbf{w}$ & $\mathbf{t}$ & $\mathbf{f}$ & $\mathbf{k}$ & $\mathbf{q}$ & $\mathbf{R}$ & $\mathbf{S}$ & \\
\hline $\begin{array}{c}\text { Values } \\
(\mathbf{m m})\end{array}$ & 1.9 & 1.6 & 2.7 & 1.3 & 1.2 & 0.3 & 1 & 0.7 & 2 & 0.3 & 1 & 0.526 & $\mathbf{\mathbf { Z }}$ \\
\hline Parameters & $\mathbf{b}$ & $\mathbf{c}$ & $\mathbf{\ell}$ & $\mathbf{y}$ & $\mathbf{z}$ & $\mathbf{A}$ & $\mathbf{B}$ & $\mathbf{C}$ & $\mathbf{D}$ & $\mathbf{T}$ & $\mathbf{Y}$ & $\mathbf{Z}$ & \\
\hline $\begin{array}{c}\text { Values } \\
(\mathbf{m m})\end{array}$ & 0.25 & 0.5 & 0.153 & 2.364 & 2 & 2 & 2.534 & 0.5 & 1 & 0.5 & 4.832 & 0.707 & \\
\hline Parameters & $\mathbf{F}$ & $\mathbf{G}$ & $\mathbf{H}$ & $\mathbf{I}$ & $\mathbf{J}$ & $\mathbf{K}$ & $\mathbf{M}$ & $\mathbf{N}$ & $\mathbf{O}$ & $\mathbf{U}$ & $\mathbf{X}$ & $\mathbf{E}$ & \\
\hline $\begin{array}{c}\text { Values } \\
(\mathbf{m m})\end{array}$ & 0.75 & 2.85 & 0.5 & 0.5 & 0.5 & 0.4 & 0.25 & 3 & 0.25 & 4 & 1 & 0.5 & \\
\hline
\end{tabular}

The slant height in the backplane is denoted by ' $\mathrm{Y}$ '. Triangular and rectangular slots are cut out in the valley shaped backplane. Rings on the edges of octagon and parameter ' $\mathrm{x}$ ' in the backplane play a major role in optimizing the S-parameter results. All the rings have the same width ' $w$ ' and diagonally opposite rings have the same inner and outer radius as being depicted in the figure. Further other dimensions are specified in the table and the design figure.

\section{STAGES OF DEVELOPMENT}

The design was simulated using computer simulation tool (CST) software. Fig. 2, shows the simulation result of the proposed antenna in three stages. In stage 01 , one side of the antenna (front view) consists of a simple dumbbell shaped octagon with its radius being $4 \mathrm{~mm}$ with the width of the microstrip line is $3 \mathrm{~mm}$ and another side of the antenna (back view) consists of valley shaped notch with the two sets of vertical slits.

In stage 01, one side of the antenna (front view) consists of a simple dumbbell shaped octagon with its 
radius being $4 \mathrm{~mm}$ with the width of the microstrip line is $3 \mathrm{~mm}$ and another side of the antenna (back view) consists of valley shaped notch with the two sets of vertical slits.

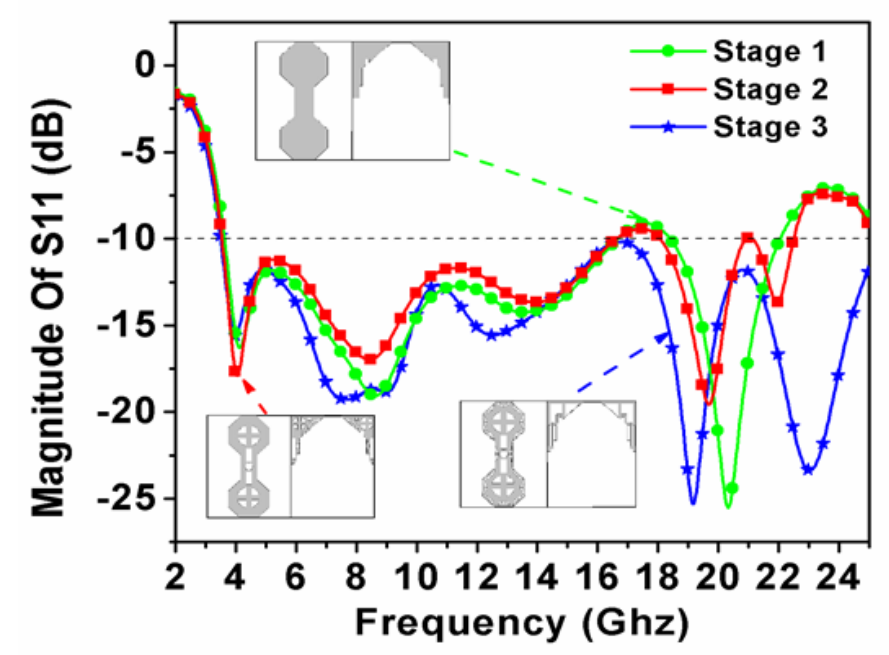

Fig. 2. Simulated return loss of stage-1, stage-2 and stage- 3 .

By introducing a dumbbell shape with valley shaped ground plane the operating frequency is resonant from 3.7 to $16.3 \mathrm{GHz}$ and 18.3 to $21.4 \mathrm{GHz}$, with the impedance bandwidth of $126 \%$ (from 3.7 to 16.3 $\mathrm{GHz}$ ) and $15.6 \%$ (from 18.3 to $21.4 \mathrm{GHz}$ ). In stage 02, introduction of circular slots in the front patch \& rectangular slits in the ground plane, increases the bandwidth of the $2^{\text {nd }}$ band from 18 to $22.4 \mathrm{GHz}$.

In stage 03 (proposed antenna), by introducing the rings on the edges of the octagon, the frequency is perfectly matched and operating frequency band resonates between $(3.7 \mathrm{GHz}$ to $25 \mathrm{GHz})$ with the impedance bandwidth of $148.48 \%$ (from $3.7 \mathrm{GHz}$ to $25 \mathrm{GHz}$ ). To further optimize the results to $3.48 \mathrm{GHz}$ impedance matching through backplane is done by varying the parameter ' $\mathrm{x}$ ', the final bandwidth of the proposed antenna is $3.48 \mathrm{GHz}$ to $25 \mathrm{GHz}$ with the impedance bandwidth of $151.11 \%$ (3.48 GHz to $25 \mathrm{GHz})$.

\section{PARAMETER STUDY}

It is done in order to optimize the results by varying the parameters which were crucial during the process of design development. Here we have studied the variation of four parameters and observed their effects on S-parameter result.

Fig. 3 shows the simulated return loss curve of the proposed antenna with the various value of ' $r$ ', which is varied from $3 \mathrm{~mm}$ to $5 \mathrm{~mm}$. initially at the value of $\mathrm{r}=3 \mathrm{~mm}$, two bands are observed from $3.9 \mathrm{GHz}$ to $14 \mathrm{GHz}$ and $16 \mathrm{GHz}$ to $25 \mathrm{GHz}$, on increasing the value of ' $\mathrm{r}$ ' the optimum results are obtained at $4 \mathrm{~mm}$. The design is synchronous with the microstrip line of width $3 \mathrm{~mm}$ at radius $4 \mathrm{~mm}$, whereas if the radius is smaller or larger, results change significantly as shown in the figure.

Fig. 4 shows the simulated return loss curve of the proposed antenna with the various value of ' $\mathrm{x}$ ', 
which is varied from $1 \mathrm{~mm}$ to $3 \mathrm{~mm}$. ' $\mathrm{x}$ ' is the length of the rectangular strip line in the backplane. By varying the value of ' $\mathrm{x}$ ' from 1 to $3 \mathrm{~mm}$, it is observed that the two band are visible in the graph at the value of ' $x=1 \mathrm{~mm}$ ' \& ' $x=3 \mathrm{~mm}$ ', the optimum results are obtained at the value of ' $x=2 \mathrm{~mm}$ ', at ' $x=2$ ' return loss from $3.48 \mathrm{GHz}$ to $25 \mathrm{GHz}$ is lesser than $-10 \mathrm{~dB}$ is observed.

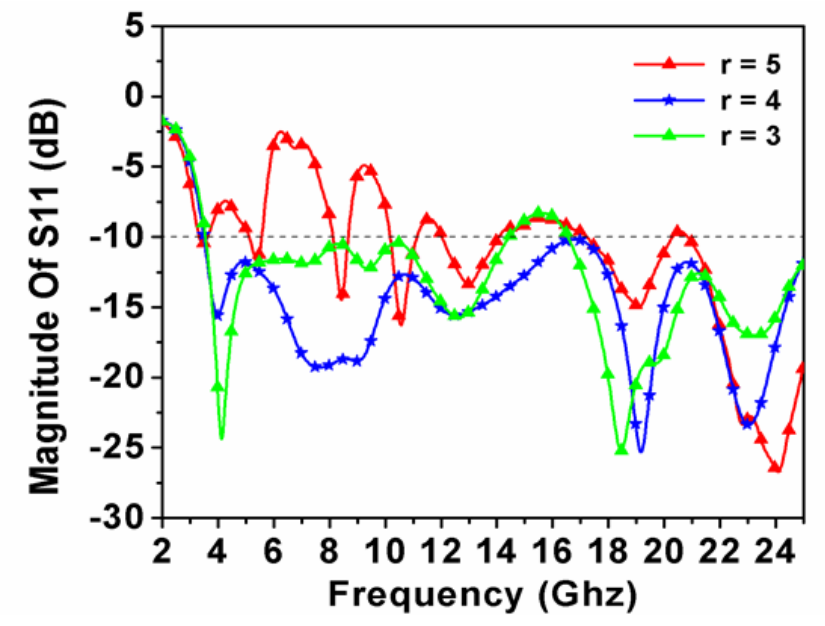

Fig. 3. Simulated return loss of proposed antenna with variations of ' $r$ '.

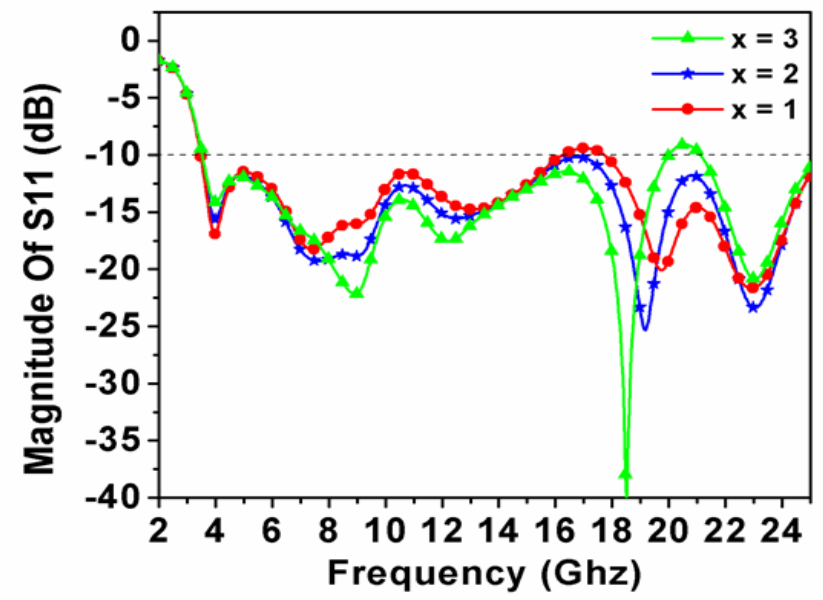

Fig. 4. Simulated return loss of proposed antenna with variations of ' $x$ '.

Fig. 5 shows the simulated return loss curve of the proposed antenna with the various value of ' $\mathrm{k}$ ', which is varied from $2 \mathrm{~mm}$ to $3 \mathrm{~mm}$. ' $\mathrm{k}$ ' is the radius of the circular slots. The optimum result is observed at $\mathrm{k}=2 \mathrm{~mm}$. At all values greater than $2 \mathrm{~mm}$ the $\mathrm{S}$-parameter results are affected significantly.

Fig. 6 shows the simulated return loss curve of the proposed antenna with the various value of ' $w$ ', which is varied from $0.3 \mathrm{~mm}$ to $0.5 \mathrm{~mm}$. ' $\mathrm{w}$ ' is the width of the rings on the edges of octagons. At $\mathrm{w}=0.4 \mathrm{~m}$ and $\mathrm{w}=0.5 \mathrm{~mm}$ return loss crosses $-10 \mathrm{~dB}$ barrier quite frequently. The results are optimized when $\mathrm{w}=0.3 \mathrm{~mm}$. 


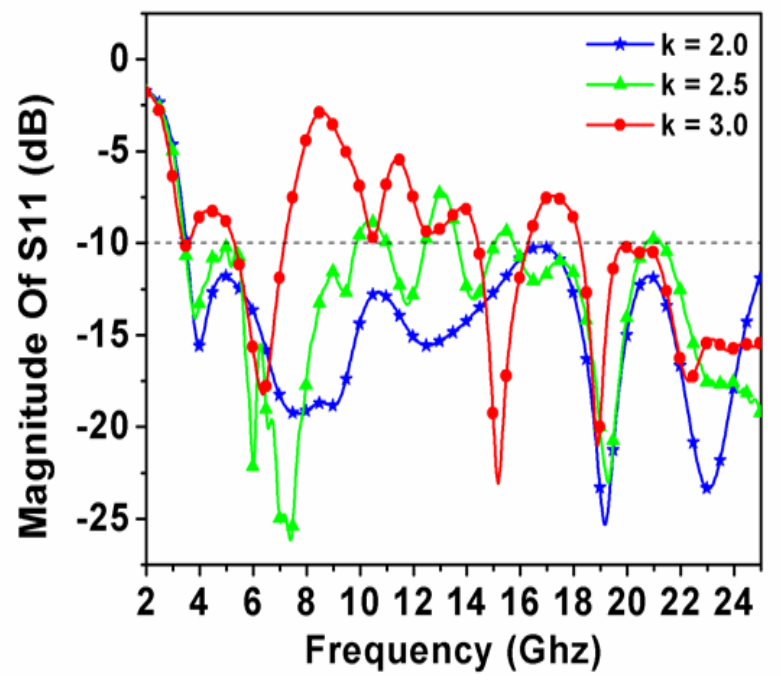

Fig. 5. Simulated return loss of proposed antenna with variations of ' $k$ '.

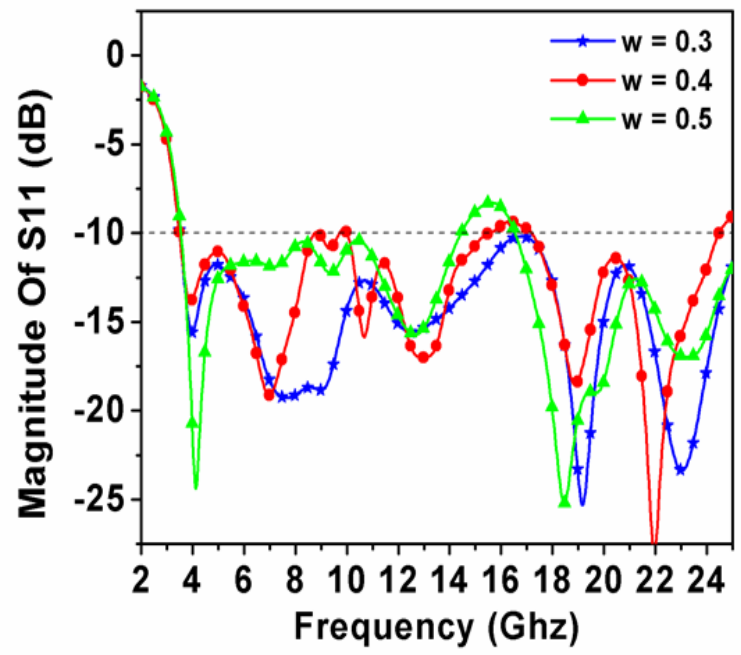

Fig. 6. Simulated return loss of proposed antenna with variations of 'w'.

\section{SIMULATED AND MEASURED RESULTS}

A dumbbell shaped broadband microstrip antenna (proposed antenna) is fabricated on a commercially available low-cost (FR-4) substrate with (electric permittivity) $\varepsilon r=4.3$ and loss tangent of 0.025 using (Phenix) chemical etching method in the antenna laboratory. The Testing of the dumbbell shaped proposed antenna measurement has been carried out using (Agilent) Vector Network Analyzer with a $50 \Omega$ SMA connector \& Anechoic Chamber.

The proposed antenna is a low profile broadband antenna which can be used in multiple wireless applications. Introduction of dumbbell octagons and valley-shaped backplane gives return loss below $10 \mathrm{~dB}$ from $3.7 \mathrm{GHz}$ to $16.3 \mathrm{GHz}$ and $18.3 \mathrm{GHz}$ to $21.4 \mathrm{GHz}$. After cutting rings on octagon edges the results are further improved to $3.7 \mathrm{GHz}$ to $25 \mathrm{GHz}$. Finally by varying ' $\mathrm{x}$ ' results are optimized to 


\section{$3.48 \mathrm{GHz}$ to $25 \mathrm{GHz}$.}

Fig. 7(a) shows the measured and simulated return loss of proposed antenna and Fig. 7(b) shows its fabrication design. It can be seen that simulated results are in good agreement with the measured results. Impedance matching is an important part in designing of any broadband antenna.

Fig. 8 shows the simulated real and imaginary parts of input impedance. The real part of the input impedance is maintained at around $50 \Omega$ and it typically varies from $40 \Omega$ to $75 \Omega$. Similarly the imaginary part of the input impedance is maintained at around $0 \Omega$ and it typically varies from $-25 \Omega$ to $10 \Omega$. It depicts that it behaves as an inductive impedance for some frequency range and capacitive impedance for the others.
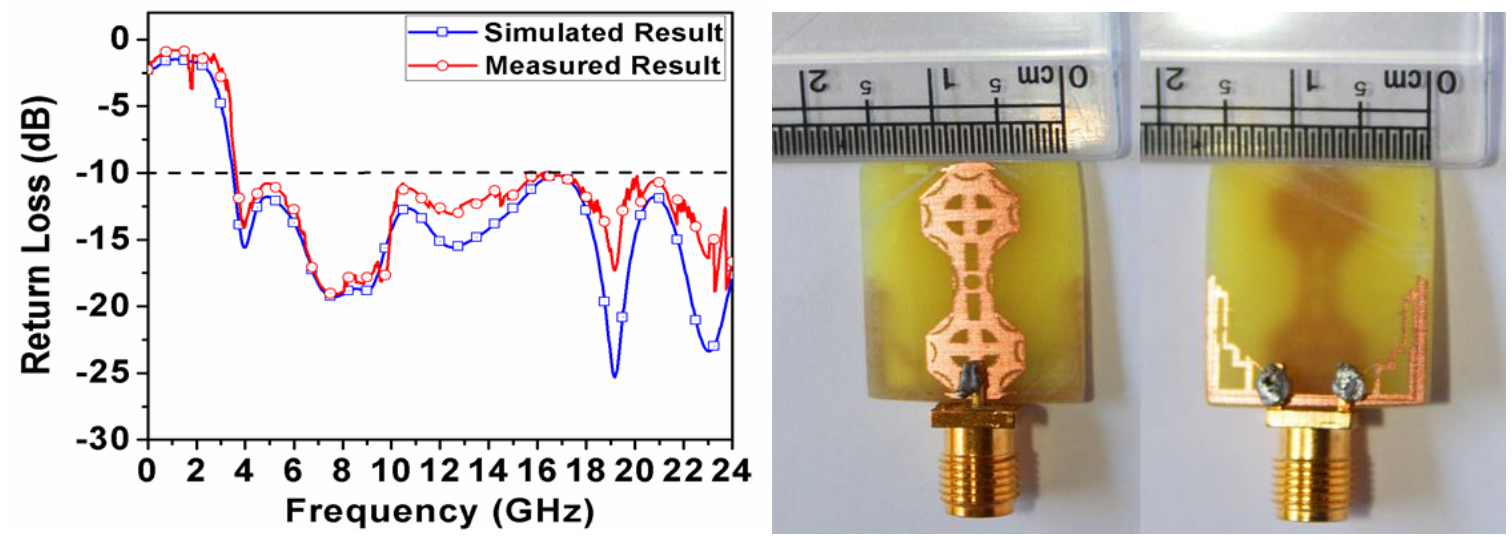

Fig.7 (a) Measured and simulated return loss of proposed antenna and (b) fabricated prototype of proposed antenna.

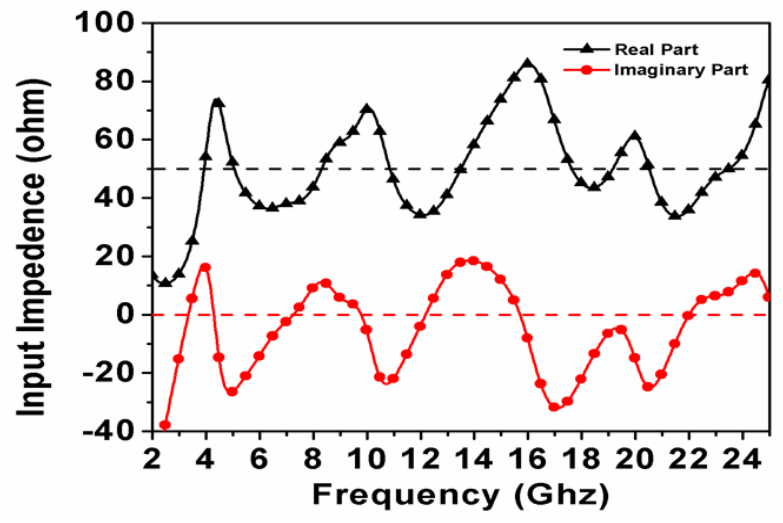

Fig. 8. Input Impedance variation of proposed antenna.

Fig. 9 shows the variation of simulated gain and radiation efficiency with frequency. Above $0 \mathrm{~dB}$, gain shows radiating signal for each frequency in the range $3.48 \mathrm{GHz}$ to $25 \mathrm{GHz}$. It can be seen from the figure that the gain gradually increases with frequency. Thus, gain is directly proportional to frequency. On the other hand radiation efficiency is decreasing gradually with increase in frequency.

The peak of the gain is obtained at $14.8 \mathrm{GHz}$ frequency, which is $4.5 \mathrm{~dB}$. Radiation efficiency is $68 \%$. Thus the proposed antenna is able to radiate in broadband frequency range due to its high gain and large 
radiation efficiency.

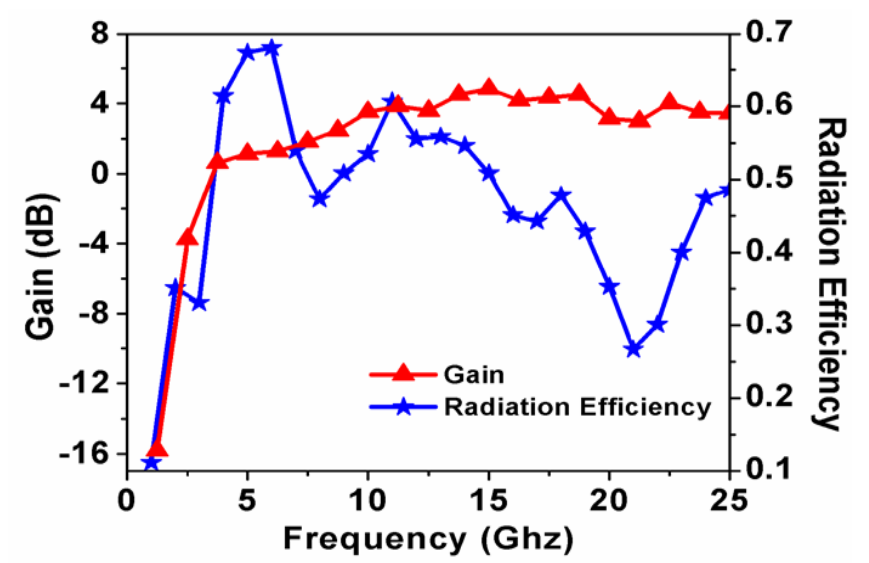

Fig. 9. Radiation efficiency and simulated gain variation of the proposed antenna.

Fig. 10 depicts the radiation pattern of the proposed antenna at four different frequencies. It shows the simulated and measured pattern of the results. From the figure both simulated and measured pattern results are in acceptable range of agreement. Radiation Pattern shows the direction of radiation by the antenna at that particular frequency. This is shown on the two perpendicular planes, which is H-plane $\left(0^{\circ}, \mathrm{x}-\mathrm{z}\right)$ and the E-plane $\left(90^{\circ}, \mathrm{y}-\mathrm{z}\right)$. At frequency $4 \mathrm{GHz}$ and $7.5 \mathrm{GHz}$, the radiation pattern is very efficient but as the frequency is increased the efficiency of the antenna gets decreased which causes unstable radiation pattern at higher frequencies.
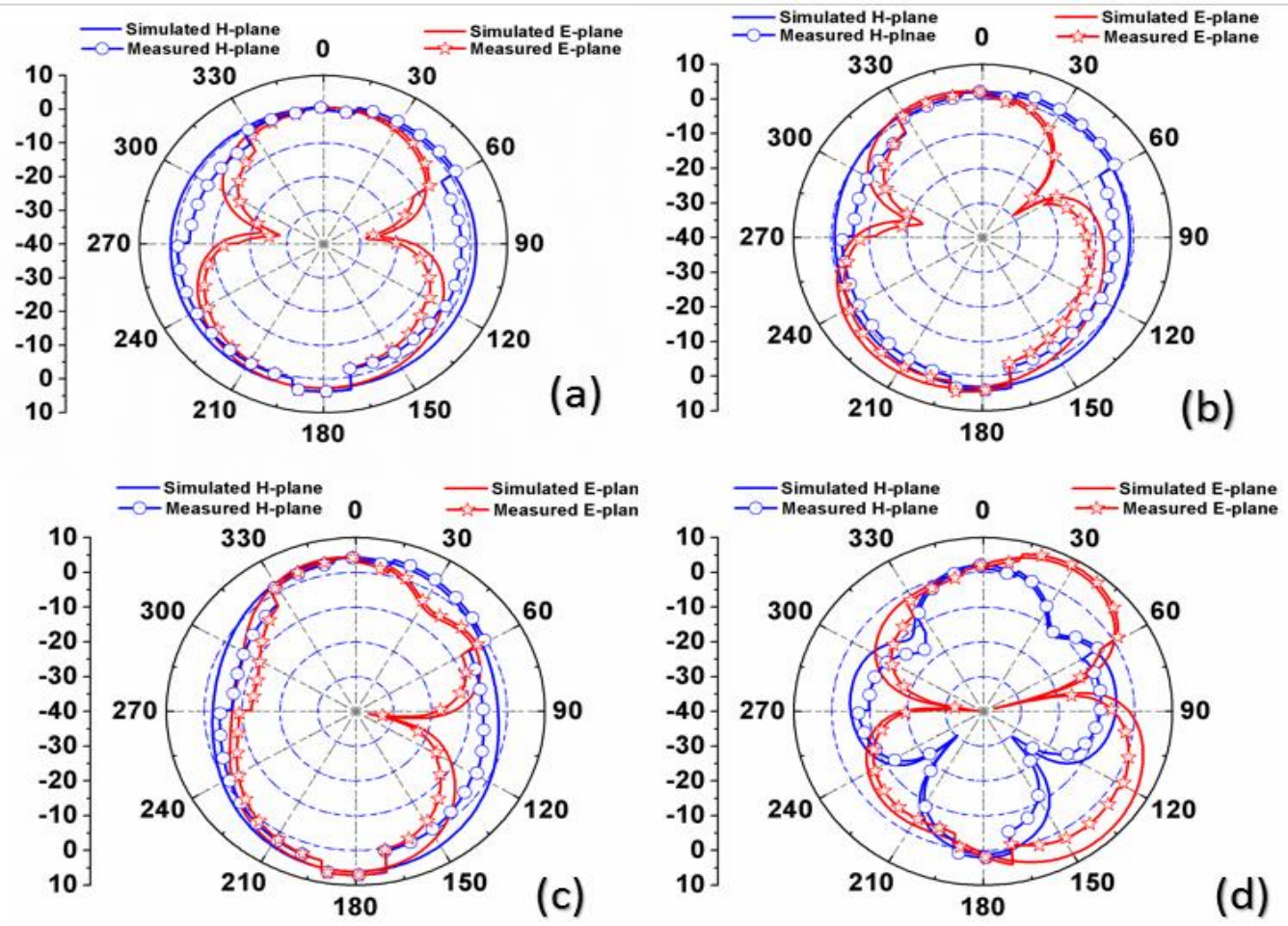

Fig. 10: Measured and Simulated radiation pattern of the proposed antenna at (a) $4 \mathrm{GHz}$ (b) $7.5 \mathrm{GHz}$ (c) $12.5 \mathrm{GHz}$ (d) $19.1 \mathrm{GHz}$. 
Fig. 11 shows the simulated results of the surface current of the proposed antenna. Higher order modes are observed at higher frequencies. At $4 \mathrm{GHz}$ frequency, only one mode is observed and as the frequency is increased, the number of modes gets increased. Since there are multiple slots in the ground plane current path increases and more number of modes are observed. The rings on edges of octagon cause generation of higher modes at higher frequency range.

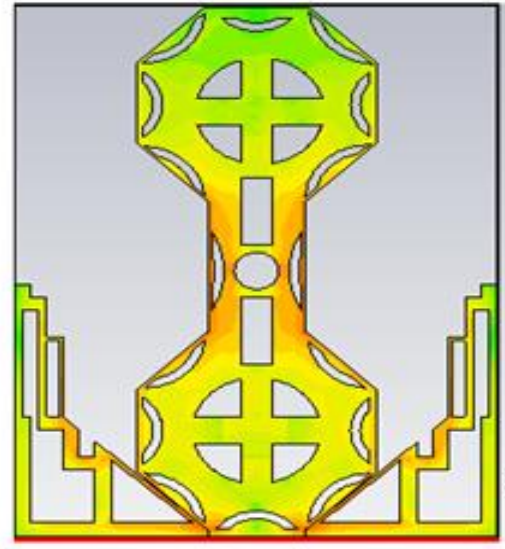

(a)

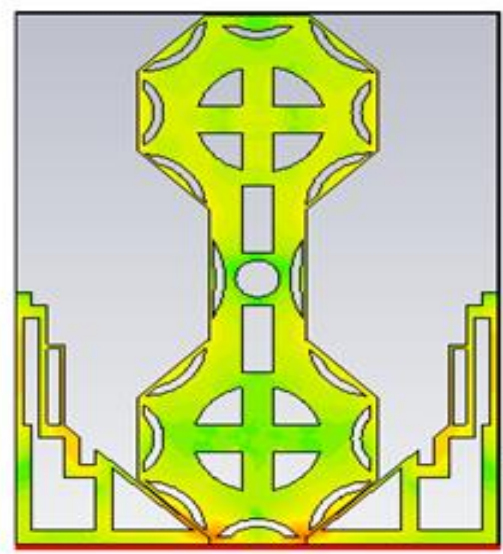

(c)

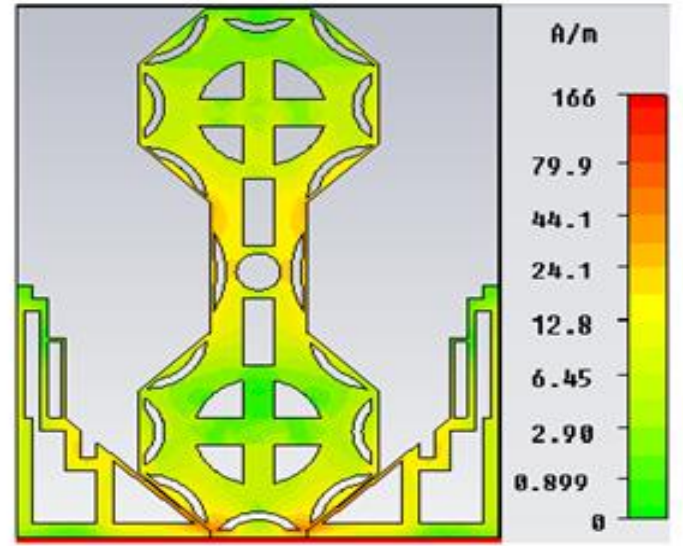

(b)

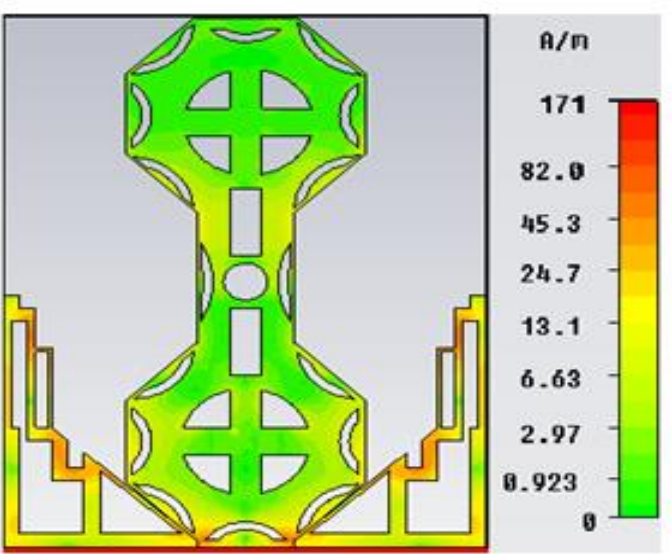

(d)

Fig. 11. Simulated surface current distribution of the proposed antenna at (a) $4 \mathrm{GHz}$ (b) $7.5 \mathrm{GHz}$ (c) $12.5 \mathrm{GHz}$ (d) $19.1 \mathrm{GHz}$.

\section{CONCLUSION}

The overall size of antenna is $20 \times 15 \times 1.5 \mathrm{~mm}^{3}$. Thus it is a very low profile antenna. Design configuration of the proposed antenna is described above and parameter study is performed using four variables in CST. The simulated results are in good agreement with the measured results covering bandwidth from $3.48 \mathrm{GHz}$ to $25 \mathrm{GHz}$. The radiation patterns of this design are stable at different frequencies. The surface current of the proposed antenna shows higher order modes at higher 
frequencies. The peak radiation efficiency is $68 \%$ at $6 \mathrm{GHz}$. The antenna can be used as a broadband antenna for multiple applications like 3.5/5.5 GHz Wimax band, 5.2/5.8 GHz WLAN band, 8/12 GHz $\mathrm{X}$-band, 12/18 GHz Ku -band, space and satellite communications.

\section{REFERENCES}

[1] M. Sun, X. Qing and Z. N. Chen, "60-GHz End-Fire Fan-Like Antennas with Wide Beamwidth," IEEE Transactions on Antennas And Propagation, vol. 61, no. 4, pp. 1616-1622, Apr. 2013.

[2] S. Baudha and D. K. Vishwakarma, "Miniaturized Dual Broadband Printed Slot Antenna with Parasitic Slot and Patch," Microwave and Optical Technology Letters, vol. 56, no.10, pp. 2260-2265, Feb. 2014.

[3] M. A. Antoniades and G.V. Eleftheriades, "A Compact Multiband Monopole Antenna with A Defected Ground Plane," IEEE Antenna Wireless Propag., vol. 7, pp. 652-655, Oct. 2008.

[4] G. D. Bhatnagar, J. S. Saini, V. K. Saxena and L. M. Joshi, "Design of Broadband Circular Patch Microstrip Antenna with Diamond Shape Slot," Indian Journal of Radio and space physics, vol. 40, no. 5, pp. 275-281, Oct. 2011.

[5] J. Kazim, A. Bibi, M. Rauf, M. Tariq and Owais, "A Compact Planar Dual Band-Notched Monopole Antenna for UWB Application,” Microwave and Optical Technology Letters, vol. 56, no. 5, pp. 1095-1097, Mar. 2014.

[6] S. Baudha and D. K. Vishwakarma, "A Compact Broadband Printed Monopole Antenna with U-Shaped Slit Rectangular Parasitic Patches," International Journal of Microwave and Wireless Technologies, vol. 8, no. 8, pp. 1231-1235, Apr. 2015.

[7] S. Baudha and D. K. Vishwakarma, "Bandwidth Enhancement of A Planar Monopole Microstrip Patch Antenna," International Journal of Microwave and Wireless Technologies, vol. 8, no. 2, pp. 237-242, Oct. 2014.

[8] Y. J. Wang, C. K. Lee, and W. J. Koh, "Single-Patch and Single-Layer Square Microstrip Antenna With 67.5\% Bandwidth,” IEEE Microw Antenna Propag., vol.148, no. 6, pp. 418-422, Dec. 2001.

[9] S. Baudha and V. Dinesh Kumar, "Corner Truncated Broadband Patch Antenna with Circular Slots," Microwave and Optical Technology Letters, vo. 57, no. 4, pp. 845-849, Apr. 2015.

[10] K. Xu, Z. Zhu, H. Li, J. Huangfu, C. Li, and L. Ran, “A Printed Single-Layer UWB Monopole Antenna with Extended Ground Plane Stubs," IEEE Antenna Wireless Propagation Letters., vol. 12, pp. 237-241, Feb. 2013.

[11] K. F. Lee, S. L. S. Yang, A.A. Kishk and K. M. Luk, "The Versatile U-Slot Patch Antenna," IEEE Antennas and Propagation Magazine, vol. 52, no. 1, pp. 71-80, May 2010.

[12] H. A. Wheeler, "Fundamental Limitations of Small Antennas," Proceedings of the IRE., vol. 35, no. 12, pp. 1479-1484, Dec. 1947.

[13] S. Baudha, D. Ahirwar, and A. Shrivastava, "A decagon shaped universal compact broadband printed monopole antenna," Microwave and Optical Technology Letters, vol. 58, no. 11, pp. 2760-2764, Mar. 2016.

[14] S. Rathore, R. Paulus, A. K. Jaiswal and A. Agrawal, "Ultra-Wideband Antenna for WLAN, Wimax and LTE Applications,” International Journal of Computer Applications, vol. 121, no. 7, pp. 27-30, Jul. 2015. 